\title{
Violência nas escolas públicas brasileiras: uma análise da relação entre o comportamento agressivo dos alunos e o ambiente escolar
}

Aggressive behavior of students in Brazilian public schools: an analysis using a fixedeffect logit model

\author{
Kalinca Léia Becker \\ Universidade Federal de Santa Maria \\ Ana Lúcia Kassouf \\ Universidade de São Paulo
}

\begin{abstract}
Interpersonal aggressions are becoming more frequent in Brazilian schools and, besides physical damage, they may affect student performance and social development. Individuals and the environment where youths live can influence their behavior. The goal of this paper is to analyze the effect of school environment on the students' violent behavior. A fixed effect logit model was estimated using a panel data of primary schools observed in Prova Brasil 2007 and 2009. The results showed that when there are violent features, such as crimes against property, persons, drug trafficking or gang activity, the probability of having students behaving aggressively is larger. Furthermore, the possibility of observing at least one assault committed by a student is 3.54 times higher in schools where a teacher displayed the same kind of behavior. To improve socialization among students we recommend extracurricular activities, and also using a grade criterion when dividing the classes.
\end{abstract}

\section{Keywords}

violence; school environment; fixed effect logit model.

JEL Codes K42; D71; C25.

\section{Resumo}

As agressões interpessoais tem se tornado cada vez mais frequentes nas escolas brasileiras e, além dos danos fisicos, podem ter consequências negativas sobre os resultados escolares e sobre a formação social dos alunos. Os individuos e as características que compõem o ambiente onde o jovem está inserido podem ter influência sobre o seu comportamento; logo, alunos em escolas com traços de violência podem também se tornar violentos. Diante desse cenário, este estudo tem como objetivo analisar alguns fatores do ambiente escolar que podem levar a ocorrência de um ato agressivo cometido por um aluno na escola. Para isso, foi estimado um modelo logit de efeito fixo, utilizando um painel de dados das escolas observadas na Prova Brasil, nos anos de 2007 e 2009. Os resultados mostraram que a possibilidade de o diretor da escola registrar pelo menos um ato agressivo de um alunoé maior em ambientes escolares com traços da violência, onde ocorreram crimes contra o patrimônio, contra a pessoa, tráfico de drogas ou atuação de gangues. Além disso, a possibilidade de se observar na escola pelo menos uma agressão física cometida por um aluno é 3,54 vezes maior em escolas em que foi observado o mesmo comportamento por parte de um professor. Algumas medidas de gestão escolar podem contribuir para facilitar a socialização dos alunos, como, por exemplo, distribuir as turmas por equivalência de nota ou promover atividades extracurriculares.

\section{Palavras-chave}

violência; ambiente escolar; modelo logit de efeito fixo.

Códigos JEL K42; D71; C25. 


\section{Introdução}

A violência na escola constitui-se em um grande problema social e pode ser vista como um comportamento agressivo que abrange os conflitos interpessoais, os danos ao patrimônio e os atos criminosos, podendo ter consequências negativas sobre os resultados escolares dos alunos. Utilizando dados de escolas nos Estados Unidos, Grogger (1997) mostrou que a violência reduz a probabilidade de um aluno concluir o ensino médio em $5,1 \%$ (high school graduation) e diminui em $6,9 \%$ a probabilidade de o aluno ingressar na faculdade. Com dados das escolas no Brasil, Sevenini e Firpo (2009) observaram que a ocorrência de um evento violento adicional em uma dada escola reduz aproximadamente $0,47 \%$ a proficiência do aluno.

Além disso, em alguns casos, jovens com problemas de comportamento tornam-se criminosos, o que não quer dizer necessariamente que um jovem com comportamento violento na escola se tornará um delinquente; porém, é de se esperar que um delinquente manifeste comportamento violento na escola. A evidência disso pode ser encontrada no estudo de Farrington (1990), que, mediante uma amostra de dados longitudinais, analisou a relação entre a agressividade manifestada na infância e os resultados na vida dos homens com 32 anos. $O$ autor observou que $57 \%$ dos homens identificados como agressivos em idade entre 8 e 10 anos foram condenados por algum tipo de crime, ao passo que, entre os indivíduos que não apresentaram agressividade na infância, o percentual observado foi de $31 \%$.

A escola tem papel fundamental na identificação do indivíduo com tendência a apresentar comportamento violento, já que é nesse ambiente que a criança provavelmente manifesta tal comportamento. Conforme Jacob e Lefgren (2003), a escola pode ainda prevenir a agressividade dos alunos por meio do ensino e do monitoramento. Essa relação é chamada de "efeito capacitação" e sugere que manter os jovens ocupados e fora das ruas pode diminuir o engajamento em atividades violentas. Todavia, os autores acrescentam que, se o ambiente escolar for caracterizado pela presença da violência, a concentração dos estudantes aumenta a probabilidade dos conflitos agressivos, uma vez que a escola proporciona a concentração geográfica dos alunos e aumenta a interação entre eles. Tal relação é denominada de "efeito concentração". 
Os resultados empíricos do estudo mostraram que o nível de crimes contra a propriedade decresceu $14 \%$ nos dias em que os jovens frequentaram a escola, o que é uma evidência do "efeito capacitação". Contudo, nesses mesmos dias, o nível de crimes violentos cresceu $28 \%$, o que os autores atribuem ao "efeito concentração" e concluem que os dois efeitos atuam dentro das escolas. É importante destacar ainda que o "efeito concentração" pode contribuir para a redução do comportamento violento dos jovens se no ambiente escolar não predominarem as ações violentas e a escola fornecer bons exemplos de conduta aos alunos, inibindo a agressividade através de punições e incentivos ao bom comportamento.

Sposito (2001) analisou vários estudos sobre a violência nas escolas do Brasil após a década de 1980 e, além de reiterar os atos de vandalismo, sobretudo contra o patrimônio escolar, observou mudanças no padrão de violência, principalmente no público infantil, em que agressões interpessoais tornaram-se comuns.

Conforme o autor, os estudos que buscam analisar a violência nas escolas no Brasil, em geral, seguem duas vertentes de interpretação - abordagem e análise. A primeira vertente busca entender o comportamento do aluno como uma forma de sociabilidade, de modo que a violência caracteriza uma falha no processo civilizatório, refletindo um conjunto de práticas escolares inadequadas, marcadas por agressões e pequenos delitos. Já a segunda vertente analisa a violência na escola como uma extensão da violência da sociedade contemporânea, visto que muitas escolas estão inseridas em áreas sob a influência do tráfico de drogas e do crime organizado. Abramovay e Rua (2002) argumentam que a disseminação do uso de drogas e a expansão do fenômeno das gangues influenciam o ambiente escolar e fazem com que as escolas deixem de ser áreas protegidas ou preservadas e tornem-se incorporadas à violência cotidiana do espaço urbano.

Nesse contexto, este estudo visa contribuir com a literatura sobre a violência nas escolas no Brasil, ao analisar e mensurar alguns fatores do ambiente escolar e do seu entorno que podem influenciar a manifestação do comportamento agressivo nos alunos. A análise é feita com base na teoria da interação social, que estabelece que o meio tem forte influência sobre o comportamento do indivíduo (Glaeser et al., 1996). Dessa forma, os fatores sociais e econômicos do ambiente escolar e o comportamento dos professores, dos pais e dos membros da comunidade local podem funcionar como exemplos de conduta para as crianças e os jovens e, assim, determinar o comportamento dos alunos. 
Este é o primeiro estudo na literatura nacional que objetiva mensurar, por meio de uma abordagem econométrica, como os fatores internos e externos ao ambiente escolar determinam o comportamento violento dos alunos. Os resultados desta pesquisa podem orientar a elaboração de políticas para a prevenção da violência na escola.

\section{Influência do meio no comportamento do jovem}

Como o jovem não tem experiência suficiente para basear suas decisões na própria vivência, muitas vezes, ele observa o comportamento dos indivíduos ao seu redor e os considera como modelos de determinada conduta. Esse comportamento é abordado pela teoria da interação social que postula que o comportamento individual depende da relação do indivíduo com a sua rede social de contatos (Freeman, 1999). Por exemplo, no caso do comportamento agressivo, um indivíduo está mais propenso a apresentar tal comportamento se os seus pares são violentos, o que é conhecido na literatura como efeito dos pares (peer effect). A evidência disso pode ser observada no estudo de Case e Katz (1991), que mostrou que pais ou irmãos mais velhos envolvidos em atividades ilegais, com passagem pela prisão ou consumo de drogas, influenciam no comportamento desse familiar, o que resulta em um efeito positivo e significativo sobre a probabilidade de o jovem envolver-se no crime.

Diante dessa ideia, muitos modelos teóricos têm sido desenvolvidos para explicar como a informação é transmitida através das redes sociais de contatos (network) e como o indivíduo processa tais informações. Banerjee (1992) desenvolveu um modelo conhecido como informação em cascata (cascade information), no qual indivíduos sequencialmente escolhem se participam de determinada atividade baseados na sua experiência e no histórico das ações de seus antecessores. Já Banerjee e Fudenberg (2004) consideraram a agregação das decisões de grande número de tomadores de decisão, que observam, além da própria experiência, os resultados das escolhas realizadas por indivíduos em períodos anteriores, conhecido como modelo de aprendizado boca a boca (word-of-mouth learning). Heavner e Lochner (2002) desenvolveram um modelo de transmissão de informação via redes sociais no caso de jovens, em que a decisão de entrada em determinada atividade é feita com base na taxa de participação dos demais 
indivíduos nessa atividade. Como resultado, os modelos de interação social constroem um "multiplicador comportamental" que pode explicar a variação nas taxas de violência entre as escolas.

Além da influência das ações dos indivíduos mais velhos, teorias no campo das Ciências Sociais e a literatura empírica evidenciam outros fatores que podem explicar por que alguns jovens se tornam agressivos, dentre os quais estão os fatores individuais e as características familiares (Farrington; Loeber, 2000; Lochner, 2004).

Os fatores individuais envolvem questões biológicas de difícil mensuração, como caráter e distúrbios psíquicos, que podem levar ao comportamento agressivo. Já as características da família envolvem fatores como: supervisão dos pais deficiente, desestruturação familiar e relacionamento afetivo pobre entre pais e filhos (Sampson; Laub, 1993). Com base no programa de pré-escola Perry para reduzir a criminalidade entre os jovens marginalizados nos Estados Unidos, Donohue e Siegelman (1994) concluíram que as intervenções de maior sucesso para reduzir a violência são aquelas realizadas nas fases iniciais do ciclo de vida e que requerem o envolvimento dos pais.

Case e Katz (1991) observaram que variáveis de estrutura familiar estão significativamente relacionadas com as variáveis de comportamento dos jovens, como, por exemplo, a variável para ambos os pais presentes até os 14 anos está negativamente relacionada com a probabilidade de o indivíduo cometer uma atividade ilegal em anos posteriores. Já no caso da variável para mãe com menos de 20 anos no momento do nascimento, a relação observada é positiva. Nesse mesmo sentido, Levitt e Lochner (2000) observaram correlação negativa entre a estrutura familiar (intactfamily) e a criminalidade.

Intervenções precoces na atividade educacional, como a creche e a educação infantil, também podem contribuir para prevenir o comportamento agressivo das crianças e, por consequência, evitar altas taxas de participação em atividades violentas e as punições decorrentes dessas atividades. Alguns autores defendem que promover a educação do indivíduo nas primeiras fases do ciclo de vida pode desenvolver noções de moralidade e civilidade, aumentando a probabilidade de o indivíduo obedecer às leis (Becker, 1968; Heckman, 2000; Lochner, 2004). É possível também que atividades que proporcionem a socialização dos alunos, como esporte, cultura e lazer, possam contribuir para prevenir o comportamento violento (Abramovay; Rua, 2002). 


\section{Metodologia}

A estratégia empírica é construir um painel de dados composto das escolas públicas observadas de 2007 e 2009. A estrutura de dados em painel permite controlar a heterogeneidade não observável entre as escolas se considerarmos que essas características não variam no tempo. Os dados utilizados são da Prova Brasil e compreendem informações de professores, diretores, alunos e escolas, em caráter universal dos alunos da $4^{\mathrm{a}}$ e da $8^{\mathrm{a}}$ séries do ensino fundamental das escolas públicas. Estima-se um modelo com uma variável dependente binária e efeitos não observados para $\mathrm{N}$ escolas, através da seguinte equação:

$$
y_{i t}=x_{i t}^{\prime} \beta+c_{i}+\varepsilon_{i t}
$$

Onde $y_{i t}$ é 1 se for registrada uma agressão física cometida por pelo menos um aluno na $i$-ésima escola $(i=1, \ldots, N)$, no ano $t(t=2007,2009)$, e 0 , caso contrário. As variáveis exógenas são representadas por $x_{i t}$ e variam no tempo; $c_{i}$ é o efeito individual de cada escola e capta características não observáveis que não variam no tempo, e $\varepsilon$ é o erro aleatório. Os pressupostos principais do modelo são:

$$
\begin{aligned}
& P\left(y_{i t}=1 \mid x_{i}, c_{i}\right)=P\left(y_{i t}=1 \mid x_{i t}, c_{i}\right)=\Lambda\left(y_{i t}=x_{i t}^{\prime} \beta+c_{i}\right), \\
& \text { e } y_{i 1}, \ldots, y_{i T} \text { são independentes e condicionais em }\left(x_{i}, c_{i}\right)
\end{aligned}
$$

onde $t=1, \ldots, T$ el é uma função logística.

Podemos estimar $y_{i t}$ considerando $c_{i}$ como um parâmetro a ser calculado juntamente com $\beta$, conhecido como modelo de efeitos fixos $(E F)$, ou considerando $c_{i}$ como uma variável aleatória não observada, selecionada juntamente com $x_{i}$ e $y_{i}$, que é o modelo de efeitos aleatórios. Geralmente, quando se trata de informações sociais, é de se esperar que os efeitos individuais estejam correlacionados com os regressores e, neste caso, o modelo de efeitos aleatórios produz estimadores inconsistentes. Essa hipótese é confirmada por meio do teste de Hausman, apresentado na Tabela A1, que mostra que o modelo mais indicado é o de efeitos fixos. $O$ teste de Hausman também foi utilizado para comparar as estimativas dos modelos 
logit de efeito fixo e logit convencional, e o resultado confirma que existe heterogeneidade não observável em c (Tabela A1).

Além dos efeitos fixos das escolas, é preciso levar em consideração a natureza binária da variável dependente. Neste caso, a estimação consistente pode ser feita por meio do estimador condicional de máxima verossimilhança, que elimina $c_{i}$ da estimativa da equação. Tal método baseia-se em encontrar a distribuição conjunta de $y_{i}=\left(y_{i 1}, \ldots, y_{i T}\right)^{\prime}$ condicional em $x_{i}, c_{i} \mathrm{e}$ $\sum_{t=1}^{T_{i}} y_{i t}$. No caso de um painel de 2 anos, condiciona-se em $y_{i 1}+y_{i 2}=1$, ou seja, $y_{i t}$ é igual a 1 em apenas um dos dois períodos:

$$
P\left(y_{i 1}=0, y_{i 2}=1 \mid y_{i 1}+y_{i 2}=1\right)=\frac{P\left(y_{i 1}=0, y_{i 2}=1\right)}{P\left(y_{i 1}=0, y_{i 2}=1\right)+P\left(y_{i 1}=1, y_{i 2}=0\right)}
$$

Supondo que $y_{i 1}$ e $y_{i 2}$ são independentes, dados $c_{i}$ e $x_{i t}$ para um modelo logit, temos:

$$
P\left(y_{i 1}=0, y_{i 2}=1\right)=\frac{1}{1+\exp \left(x_{i 1}^{\prime} \beta+c_{i}\right)} \times \frac{\exp \left(x_{i 2}^{\prime} \beta+c_{i}\right)}{1+\exp \left(x_{i 2}^{\prime} \beta+c_{i}\right)}
$$

e

$$
P\left(y_{i 1}=1, y_{i 2}=0\right)=\frac{\exp \left(x_{i 1}^{\prime} \beta+c_{i}\right)}{1+\exp \left(x_{i 1}^{\prime} \beta+c_{i}\right)} \times \frac{1}{1+\exp \left(x_{i 2}^{\prime} \beta+c_{i}\right)}
$$

Substituindo (5) e (6) em (4), temos:

$$
\begin{aligned}
& P\left(y_{i 1}=0, y_{i 2}=1 \mid y_{i 1}+y_{i 2}=1\right)=\frac{\exp \left(x_{i 2}^{\prime} \beta+c_{i}\right)}{\exp \left(x_{i 1}^{\prime} \beta+c_{i}\right)+\exp \left(x_{i 2}^{\prime} \beta+c_{i}\right)}= \\
& =\frac{\exp \left(x_{i 2}^{\prime} \beta\right)}{\exp \left(x_{i 1}^{\prime} \beta\right)+\exp \left(x_{i 2}^{\prime} \beta\right)}
\end{aligned}
$$

Ao condicionar em $\sum_{t=1}^{T_{i}} y_{i t}$, porém, perdemos as observações onde $y_{i t}$ é 0 ou 1 para todo $t$. Além disso, Wooldridge (2002) ressalta que não é possível afirmar que esse procedimento é condicionado nos efeitos não observados, de modo que não é possível avaliar diretamente os efeitos parciais das variáveis independentes sobre a probabilidade de resposta. Por outro lado, tal abordagem baseia-se em estimar a densidade condicional que permite identificar os coeficientes estruturais da amostra. 
Dee (2005) sugere que a magnitude dos coeficientes estimados pode ser interpretada através da oddsratio, que é a razão entre a odds, ${ }^{1}$ considerando uma alteração de uma unidade em uma variável independente, mantidas constantes as demais variáveis, e a odds sem considerar essa alteração. Dessa forma, a oddsratio corresponde ao fator estimado para o qual uma variável independente influencia a possibilidade de um resultado "favorável" da variável dependente binária. O autor comparou esses resultados com os das estimativas de mínimos quadrados ordinários, baseadas em um modelo de probabilidade linear com efeito fixo, e encontrou resultados similares. Thompson (2006) também utiliza a oddsratio para interpretar os coeficientes estruturais do modelo logit de efeito fixo, obtidos por meio do estimador condicional de máxima verossimilhança.

\subsection{Descrição das variáveis}

A proposta deste estudo é analisar se o ambiente escolar influencia a possibilidade de ocorrer na escola uma agressão física cometida por um aluno. As informações das características socioeconômicas dos alunos e suas famílias foram obtidas por meio do questionário do aluno da Prova Brasil de 2007 e 2009. Já as informações da escola e do ambiente escolar foram arroladas via questionário do diretor. A variável dependente é uma binária com valor 1 se o diretor da escola reportou, no questionário da Prova Brasil, pelo menos uma agressão física cometida por um aluno, contra um professor, um funcionário ou outro aluno, e zero, caso contrário.

Uma limitação da análise, decorrente da utilização dos dados da Prova Brasil, é que não há informação de quantas agressões ocorreram na escola, mas apenas se ocorreram ou não. As informações disponíveis para as situações de violência são respondidas pelos diretores que reportam se, por exemplo, no ano de aplicação do questionário, houve agressão física e se o agressor foi um aluno. Sendo assim, uma escola em que ocorreu apenas um caso de violência é tratada da mesma forma que uma escola onde ocorreram inúmeros casos.

Outra limitação, destacada por Grogger (1997) e Severnini e Firpo (2009), é o fato de as respostas estarem sujeitas à análise subjetiva dos diretores, registrar uma agressão cometida por um aluno, no período $t$ (Pampel, 2000). 
que podem responder às perguntas de forma estratégica, no caso de as respostas sobre a violência escolar determinarem a alocação de recursos públicos ou se forem utilizadas como medida da qualidade da gestão escolar.

Para observar como o comportamento agressivo dos professores influencia o mesmo tipo de comportamento nos alunos, foi incluída no modelo a variável binária agressão do professor, para distinguir as escolas onde o diretor reportou pelo menos uma agressão física cometida por um professor contra um colega ou um funcionário daquelas escolas nas quais o diretor não reportou tais ações. Essa variável é incluída no modelo como Proxy da taxa de participação na atividade violenta, visto que, conforme o modelo de Heavner e Lochner (2002), os indivíduos baseiam suas decisões nos resultados e na taxa de participação dos seus antecessores.

É de se esperar que o comportamento dos professores funcione como exemplo de conduta para os jovens. Nisso, baseia-se o argumento para considerar essa variável potencialmente exógena, já que, com base na teoria, os indivíduos mais jovens tomam suas decisões observando as ações dos mais velhos. Na prática, porém, é possível que a ação agressiva dos alunos possa interferir no comportamento do professor, e, neste caso, haverá causalidade reversa. Na tentativa de minimizar tal problema, não foram consideradas as agressões contra alunos para compor a variável de agressão do professor, uma vez que a ação violenta de um aluno em sala de aula pode motivar uma reação no professor.

Para observar se o ambiente escolar caracterizado como violento influencia a manifestação desse mesmo tipo de comportamento nos alunos, foi definido um grupo de variáveis que caracterizam ações violentas, em que o agente causador é externo à escola. ${ }^{2}$ Por hipótese, o comportamento violento de um agente externo dentro da escola poderia influenciar o comportamento dos alunos; já o comportamento agressivo de um aluno dentro da escola não teria influência sobre o comportamento de um agente externo.

A variável binária crime contra o patrimônio diferencia a ocorrência de furto, depredação ou pichação das dependências da escola da não ocorrência desse tipo de crime. A variável binária crime contra a pessoa diferencia a ocorrência de roubo com uso de violência ou atentado à vida da não ocorrência desse tipo de crime (categoria omitida). A variável binária tráfico de drogas diferencia o tráfico de drogas nas dependências ou nas proximidades

$2 \bigcirc$ questionário do diretor da Prova Brasil diferencia a ação violenta de agente causador externo (estranho à escola) ou interno (da própria escola). 
da escola da não ocorrência de tráfico de drogas (categoria omitida). Já a variável binária gangues diferencia a ação de gangues nas dependências externas e internas da escola da inexistência de gangues (categoria omitida).

Uma limitação relacionada às variáveis de violência deriva do fato de que muitas crianças estudam em escolas próximas ao local de residência $\mathrm{e}$, ao interagirem no ambiente ao redor da escola, podem influenciar o comportamento dos agentes externos. Dessa forma, é possível que exista causalidade reversa se o comportamento agressivo de um aluno contra um colega, professor ou funcionário influenciar as ações violentas dos agentes externos, supondo que essas ações sejam cometidas por moradores dos arredores da escola. Para controlar esse tipo de questão, são necessárias variáveis instrumentais correlacionadas com a variável potencialmente endógena que, neste estudo, são as variáveis de violência na escola, e não correlacionadas com o erro da equação (1). Contudo, obter bons instrumentos não é uma tarefa simples e dificilmente tais variáveis estão disponíveis nos bancos de dados.

Dada essa dificuldade, muitos estudos que visam mensurar a influência do meio no comportamento dos jovens não levam em consideração a causalidade reversa. Case e Katz (1991), um dos principais trabalhos nessa literatura, analisaram a probabilidade de um jovem ser usuário de drogas ilícitas utilizando como regressor um membro da família com problemas de drogas/álcool. Mocan e Rees (2005) analisaram a probabilidade de um jovem se envolver em um crime utilizando como regressor a taxa de crimes na região de residência.

Foi definido um segundo grupo de variáveis relacionadas à escola para observar se medidas ou políticas de gestão escolar podem contribuir para reduzir a violência dos alunos. A variável binária medidas de segurança diferencia escolas que adotam alguma medida de segurança para proteger os alunos nas suas imediações daquelas que não adotam tais medidas (categoria omitida). Esta variável é introduzida no modelo para observar se a tentativa de reduzir o contato dos alunos com o ambiente no entorno da escola caracterizado como violento pode contribuir para que o aluno não reproduza o mesmo comportamento dentro da escola.

Os locais que os alunos normalmente preferem nas escolas são as cantinas ou as lanchonetes, as bibliotecas, os centros de informática, os ginásios de esportes, os laboratórios e os pavilhões de artes. Promover um ambiente agradável e atividades de esporte, integração e cultura nesses locais 
pode contribuir para o processo de socialização dos alunos (Abramovay; Rua; 2002). Para observar se atividades extracurriculares podem influenciar o comportamento dos alunos, é incluída no modelo a variável binária atividade extracurricular para diferenciar escolas que desenvolvem atividades esportivas e atividades artísticas daquelas que não desenvolvem atividades extracurriculares (categoria omitida).

Promover a convivência de alunos com características distintas pode levar a algum tipo de conflito entre as partes e levar ao comportamento violento. Para observar essa questão, foram definidas duas variáveis binárias para o critério da formação das turmas nas escolas. A primeira delas é turmas formadas por idade que diferencia escolas que formam as turmas com alunos em idades similares daquelas que não adotam esse critério (categoria omitida). Com a mesma estrutura, foi definida a variável turmas formadas por nota.

Promover a educação na primeira infância pode facilitar o processo de socialização da criança, torná-la mais paciente e desenvolver noções de moralidade e civilidade, o que pode contribuir para reduzir o comportamento agressivo (Becker, 1968; Becker; Mulligan, 1997; Heckman, 2000; Lochner, 2004). Para observar se intervenções precoces na atividade educacional podem contribuir para reduzir a violência, foi introduzida no modelo a variável creche, que é a proporção de alunos na escola que frequentaram a creche.

Foram também definidas variáveis das características das famílias dos alunos. A primeira delas é a média, por escola, do que denominamos de "indicador do nível de vida dos alunos". Esse indicador é construído utilizando-se o método de componentes principais, considerando-se 10 variáveis que representam a existência ou não de bens na residência dos alunos, que são: televisão, rádio, DVD, geladeira, freezer, máquina de lavar roupa, carro, computador, banheiro e profissional de serviços domésticos.

O primeiro componente principal foi definido como a variável nível de vida, uma vez que explica aproximadamente $47 \%$ da variância total dos dados em 2007 e 45\% em 2009. A Tabela 1 apresenta os autovetores (ou coeficientes das combinações lineares), obtidos com base na matriz de correlação das variáveis originais, que indicam qual a importância de cada uma das variáveis no primeiro componente principal.

A variável reunião representa a proporção de alunos em uma determinada escola que responderam que os responsáveis vão sempre ou quase sempre às reuniões de pais. Essa variável representa o envolvimento dos pais com as atividades escolares dos filhos, já que o estudo de Donohue e Siegelman 
(1994) conclui que as intervenções mais eficazes para prevenir a criminalidade dos jovens são aquelas que requerem maior participação dos pais.

A variável lar uniparental feminino é a proporção de crianças na escola que responderam que moram com a mãe ou com uma mulher responsável, mas não moram com o pai ou um homem responsável. Essa variável é incluída no modelo com base nos estudos de Case e Katz (1991) e Levitt e Lochner (2000), que observaram que a estrutura familiar está relacionada com as variáveis de comportamento dos jovens.

Tabela 1 Coeficientes das combinações lineares da análise de componentes principais

\begin{tabular}{lrr}
\hline Variáveis & Autovetor & Autovetor \\
\hline DVD & $\mathbf{2 0 0 7}$ & $\mathbf{2 0 0 9}$ \\
\hline Televisão & 0,367 & 0,3503 \\
\hline Rádio & 0,2929 & 0,2709 \\
\hline Geladeira & 0,246 & 0,2581 \\
\hline Freezer & 0,369 & 0,3615 \\
\hline Máquina de lavar roupa & 0,2539 & 0,1584 \\
\hline Carro & 0,3718 & 0,3711 \\
\hline Computador & 0,3782 & 0,3849 \\
\hline Banheiro & 0,3936 & 0,4127 \\
\hline Profissional de serviços domésticos & 0,2634 & 0,3417 \\
\hline Autovalor & 0,1132 & 0,0921 \\
\hline Fon & $\mathbf{4 , 6 9 7 6}$ & $\mathbf{4 , 5 3 3 3}$ \\
\hline
\end{tabular}

Fonte: Elaboração do autor com base nos microdados da Prova Brasil de 2007 e 2009.

Por fim, foi incluída no modelo a variável binária de tempo, na qual a categoria omitida é o ano de 2007. As estimativas foram ponderadas pelo número de alunos nas escolas, de forma a atribuir maior importância às informações das escolas maiores.

\section{Análise descritiva dos dados}

Nesta seção, é traçado o perfil das escolas que compõem a amostra. Os dados são de escolas públicas, e as informações dos alunos referem-se à $4^{a}$ e à $8^{a}$ séries do ensino fundamental, disponibilizados nas Provas Brasil de 2007 e 2009. Foram observadas 6.726 escolas que possuem informação em todas as variá- 
veis do modelo econométrico, totalizando 13.452 observações nos dois anos analisados. As estatísticas descritivas das variáveis de violência nas escolas, do ambiente escolar e das características das famílias dos alunos estão na Tabela 2.

Tabela 2 Estatísticas descritivas dos indicadores de violência nas escolas, do ambiente escolar das características das famílias dos alunos

\begin{tabular}{|c|c|c|c|}
\hline Variáveis & 2007 & 2009 & $t$ \\
\hline \multirow{2}{*}{ Agressão do aluno } & 0,4755 & 0,469 & 1,363 \\
\hline & $(0,0006)$ & $(0,0006)$ & \\
\hline \multirow{2}{*}{ Agressão do professor } & 0,0191 & 0,0168 & 0,1366 \\
\hline & $(0,0002)$ & $(0,0002)$ & \\
\hline \multirow{2}{*}{ Crime contra o patrimônio } & 0,4739 & 0,4641 & 0,4743 \\
\hline & $(0,0006)$ & $(0,0006)$ & \\
\hline \multirow{2}{*}{ Crime contra a pessoa } & 0,0989 & 0,1159 & $-3,5209$ \\
\hline & $(0,0004)$ & $(0,0004)$ & \\
\hline \multirow{2}{*}{ Tráfico de drogas } & 0,3985 & 0,4189 & $-1,8645$ \\
\hline & $(0,0006)$ & $(0,0006)$ & \\
\hline \multirow{2}{*}{ Atuação de gangues } & 0,2447 & 0,2328 & 1,7123 \\
\hline & $(0,0005)$ & $(0,0005)$ & \\
\hline \multirow{2}{*}{ Medidas de segurança } & 0,3629 & 0,3987 & $-2,9391$ \\
\hline & $(0,0006)$ & $(0,0006)$ & \\
\hline \multirow{2}{*}{ Atividade extracurricular } & 0,8951 & 0,8828 & 1,7094 \\
\hline & $(0,0004)$ & $(0,0004)$ & \\
\hline \multirow{2}{*}{ Turmas formadas por idade } & 0,5733 & 0,5711 & 0,211 \\
\hline & $(0,0006)$ & $(0,0006)$ & \\
\hline \multirow{2}{*}{ Turmas formadas por nota } & 0,9335 & 0,9432 & $-1,7817$ \\
\hline & $(0,0003)$ & $(0,0003)$ & \\
\hline \multirow{2}{*}{ Creche } & 0,7767 & 0,7732 & 2,0087 \\
\hline & $(0,0002)$ & $(0,0001)$ & \\
\hline \multirow{2}{*}{ Nível de vida } & 0,2053 & 0,2382 & 1,5675 \\
\hline & $(0,0008)$ & $(0,0006)$ & \\
\hline \multirow{2}{*}{ Reunião } & 0,6166 & 0,6109 & 2,7812 \\
\hline & $(0,0002)$ & $(0,0002)$ & \\
\hline \multirow{2}{*}{ Lar uniparental feminino } & 0,2963 & 0,3047 & $-4,7672$ \\
\hline & $(0,0001)$ & $(0,0001)$ & \\
\hline
\end{tabular}

Fonte: Elaboração do autor com base nos microdados da Prova Brasil de 2007 e 2009.

Nota: Erro padrão entre parênteses. As estimativas foram ponderadas pelo número de alunos nas escolas. 
Tabela 3 Vítimas de agressões físicas cometidas por alunos e professores

\begin{tabular}{l|r|r|r|r|r|r|r|r}
\hline \multirow{2}{*}{ Anos } & \multicolumn{3}{|c|}{ Agressão cometida por aluno contra } & \multicolumn{3}{|c|}{ Agressão cometida por professor contra } \\
\cline { 2 - 9 } & Aluno & Professor & $\begin{array}{r}\text { Funcio- } \\
\text { nário }\end{array}$ & Total & Aluno & Professor & $\begin{array}{r}\text { Funcio- } \\
\text { nário }\end{array}$ & Total \\
\hline \multirow{2}{*}{2007} & 2.704 & 435 & 266 & 3.405 & 106 & 76 & 43 & 225 \\
\cline { 2 - 10 } & $(79 \%)$ & $(13 \%)$ & $(8 \%)$ & $(100 \%)$ & $(47 \%)$ & $(34 \%)$ & $(19 \%)$ & $(100 \%)$ \\
\hline \multirow{2}{*}{2009} & 2.594 & 429 & 308 & 3.331 & 76 & 71 & 48 & 195 \\
\cline { 2 - 9 } & $(78 \%)$ & $(13 \%)$ & $(9 \%)$ & $(100 \%)$ & $(39 \%)$ & $(36 \%)$ & $(25 \%)$ & $(100 \%)$ \\
\hline
\end{tabular}

Fonte: Elaboração do autor com base nos microdados da Prova Brasil de 2007 e 2009.

Tabela 4 Proporção de registros de agressão física cometida por aluno, condicional às variáveis que caracterizam a presença da violência no ambiente escolar

\begin{tabular}{|c|c|c|c|c|c|c|}
\hline \multirow{2}{*}{ Variáveis } & & \multicolumn{2}{|r|}{2007} & \multicolumn{2}{|r|}{2009} & \multirow{2}{*}{ (2007/2009) } \\
\hline & & Ocorreu & Não ocorreu & Ocorreu & Não ocorreu & \\
\hline \multirow{3}{*}{$\begin{array}{l}\text { Agressão do } \\
\text { professor }\end{array}$} & Sim & $78 \%$ & $22 \%$ & $74 \%$ & $26 \%$ & $(0,10)$ \\
\hline & Não & $43 \%$ & $57 \%$ & $40 \%$ & $60 \%$ & $(1,48)$ \\
\hline & & $(7,59)$ & & $(6,10)$ & & \\
\hline \multirow{3}{*}{$\begin{array}{l}\text { Crime contra o } \\
\text { patrimônio }\end{array}$} & Sim & $57 \%$ & $43 \%$ & $52 \%$ & $48 \%$ & $(1,48)$ \\
\hline & Não & $36 \%$ & $64 \%$ & $33 \%$ & $67 \%$ & $(0,43)$ \\
\hline & & $(15,42)$ & & $(16,72)$ & & \\
\hline \multirow{3}{*}{$\begin{array}{l}\text { Crime contra a } \\
\text { pessoa }\end{array}$} & Sim & $62 \%$ & $38 \%$ & $61 \%$ & $39 \%$ & $(0,68)$ \\
\hline & Não & $43 \%$ & $57 \%$ & $39 \%$ & $61 \%$ & $(1,70)$ \\
\hline & & $(10,94)$ & & $(10,18)$ & & \\
\hline \multirow{3}{*}{ Tráfico de drogas } & Sim & $60 \%$ & $40 \%$ & $57 \%$ & $43 \%$ & $(0,81)$ \\
\hline & Não & $36 \%$ & $64 \%$ & $33 \%$ & $67 \%$ & $(1,71)$ \\
\hline & & $(20,17)$ & & $(19,40)$ & & \\
\hline \multirow{3}{*}{$\begin{array}{l}\text { Atuação de } \\
\text { gangues }\end{array}$} & Sim & $67 \%$ & $33 \%$ & $65 \%$ & $35 \%$ & $(0,22)$ \\
\hline & Não & $39 \%$ & $61 \%$ & $35 \%$ & $65 \%$ & $(1,00)$ \\
\hline & & $(18,95)$ & & $(18,98)$ & & \\
\hline
\end{tabular}

Fonte: Elaboração do autor com base nos microdados da Prova Brasil de 2007 e 2009.

Nota: Estatística t entre parênteses. As estimativas foram ponderadas pelo número de alunos nas escolas.

É preocupante observar que aproximadamente 47\% das escolas registraram o comportamento violento de pelo menos um aluno. Agressões cometidas por professores contra colegas ou funcionários foram observadas em aproximadamente $2 \%$ das escolas da amostra. $O$ valor $t$ do teste de dife- 
rença entre as médias nos anos de 2007 e 2009 não foi significativo a 10\% para as variáveis agressão do aluno, agressão do professor, crime contra o patrimônio, turmas formadas por idade e nível de vida.

A maioria das agressões de alunos é cometida contra outro aluno, 79\% em 2007 e 78\% em 2009, e 13\% são contra professores (Tabela 3). As agressões cometidas por professores também são, em maioria, contra os alunos, 47\% em 2007 e 39\% em 2009. As agressões contra colegas também são frequentes, 34\% em 2007 e 36\% em 2009.

$\mathrm{Na}$ Tabela 4, é possível observar que agressões físicas de alunos são mais comuns em escolas caracterizadas pela presença da violência. Em mais de $74 \%$ das escolas onde foi registrada uma agressão física cometida por um professor, ocorreu também agressão física cometida por alunos. Já nas escolas onde não foi registrada agressão de professores, esse valor é de aproximadamente $40 \%$. A mesma relação pode ser observada nas demais variáveis. Em escolas onde ocorreu crime contra o patrimônio, contra a pessoa, tráfico de drogas ou atuação de gangues, a porcentagem de registros de agressão física de alunos é maior em comparação às escolas nas quais não ocorreram ações que caracterizam um ambiente escolar violento.

O valor $t$ do teste de médias indica a significância estatística das diferenças na proporção de registros de agressão física cometida por aluno entre as escolas onde o diretor reportou ações violentas e aquelas onde não houve tais registros. Já as comparações de médias entre os anos de 2007 e 2009 foram significativas a $10 \%$ apenas para as escolas em que o diretor não reportou crime contra a pessoa e tráfico de drogas, e a proporção de registros de agressão física cometida por alunos foi, perspectivamente, $43 \%$ e $36 \%$, em 2007, e 39\% e 33\%, em 2009.

Algumas medidas de gestão escolar podem contribuir para reduzir a violência. $\mathrm{Na}$ Tabela 5 , observa-se que a porcentagem de agressões cometidas por alunos em escolas que adotaram alguma medida de segurança para protegê-los das imediações é menor que nas escolas que não adotaram tais medidas, com significância de $5 \%$.

A proporção de escolas em que se observa agressividade dos alunos é um pouco menor nas escolas que formam as turmas por idade, com significância de 10\%. A mesma relação não é observada nas escolas que formam as turmas pelas notas dos alunos, cujas diferenças não são significativas, assim como nas escolas que realizam atividades extracurriculares com os alunos. 
Tabela 5 Proporção de registros de agressão física cometida por aluno, condicional às variáveis que caracterizam ações para reduzir a violência nas escolas

\begin{tabular}{|c|c|c|c|c|c|c|}
\hline \multirow{2}{*}{ Variáveis } & & \multicolumn{2}{|r|}{2007} & \multicolumn{2}{|r|}{2009} & $t$ \\
\hline & & Ocorreu & Não ocorreu & Ocorreu & Não ocorreu & (2007/2009) \\
\hline \multirow{3}{*}{$\begin{array}{l}\text { Medidas de } \\
\text { segurança }\end{array}$} & Sim & $43 \%$ & $57 \%$ & $39 \%$ & $61 \%$ & $(0,57)$ \\
\hline & Não & $45 \%$ & $55 \%$ & $42 \%$ & $58 \%$ & $(1,17)$ \\
\hline & & $(-2,31)$ & & $(-2,63)$ & & \\
\hline \multirow{3}{*}{$\begin{array}{l}\text { Atividade } \\
\text { extracurricular }\end{array}$} & Sim & $45 \%$ & $55 \%$ & $41 \%$ & $59 \%$ & $(1,36)$ \\
\hline & Não & $42 \%$ & $58 \%$ & $40 \%$ & $60 \%$ & $(0,19)$ \\
\hline & & $(0,81)$ & & $(1,22)$ & & \\
\hline \multirow{3}{*}{$\begin{array}{l}\text { Turmas formadas } \\
\text { por idade }\end{array}$} & Sim & $43 \%$ & $57 \%$ & $40 \%$ & $60 \%$ & $(0,68)$ \\
\hline & Não & $46 \%$ & $54 \%$ & $42 \%$ & $58 \%$ & $(1,31)$ \\
\hline & & $(-1,65)$ & & $(-2,47)$ & & \\
\hline \multirow{3}{*}{$\begin{array}{l}\text { Turmas formadas } \\
\text { por nota }\end{array}$} & Sim & $44 \%$ & $56 \%$ & $41 \%$ & $59 \%$ & $(1,52)$ \\
\hline & Não & $44 \%$ & $56 \%$ & $40 \%$ & $60 \%$ & $(0,33)$ \\
\hline & & $(0,31)$ & & $(1,35)$ & & \\
\hline
\end{tabular}

Fonte: Elaboração do autor com base nos microdados da Prova Brasil de 2007 e 2009.

Nota: Estatísticat entre parênteses. As estimativas foram ponderadas pelo número de alunos nas escolas.

Tabela 6 Médias das variáveis das características dos alunos nas escolas, condicional ao registro de agressão física cometida por aluno

\begin{tabular}{|c|c|c|c|c|c|c|}
\hline \multirow{2}{*}{ Variáveis } & \multicolumn{2}{|r|}{2007} & \multicolumn{2}{|r|}{2009} & \multicolumn{2}{|c|}{$t(2007 / 2009)$} \\
\hline & Ocorreu & Não ocorreu & Ocorreu & Não ocorreu & Ocorreu & Não ocorreu \\
\hline \multirow{2}{*}{ Creche } & 0,7827 & 0,7714 & 0,7733 & 0,7731 & $(3,41)$ & $(-0,22)$ \\
\hline & $(3,43)$ & & $(4,10)$ & & & \\
\hline \multirow{2}{*}{ Nível de vida } & 0,1975 & 0,3821 & 0,2361 & 0,2795 & $(-3,70)$ & $(3,02)$ \\
\hline & $(-5,78)$ & & $(-1,52)$ & & & \\
\hline \multirow{2}{*}{ Reunião } & 0,5951 & 0,6002 & 0,5943 & 0,5981 & $(1,62)$ & $(2,29)$ \\
\hline & $(-0,86)$ & & $(-1,22)$ & & & \\
\hline \multirow{2}{*}{$\begin{array}{l}\text { Lar unipar. } \\
\text { feminino }\end{array}$} & 0,3113 & 0,2984 & 0,3037 & 0,2898 & $(3,12)$ & $(3,74)$ \\
\hline & $(5,79)$ & & $(5,43)$ & & & \\
\hline
\end{tabular}

Fonte: Elaboração do autor com base nos microdados da Prova Brasil de 2007 e 2009.

Nota: Estatísticat entre parênteses. As estimativas foram ponderadas pelo número de alunos nas escolas.

Aproximadamente $77 \%$ das crianças da amostra frequentaram a creche (Tabela 2). Esse valor é bastante similar entre as escolas onde foi registrada uma agressão física de um aluno e as escolas que não registraram um aconteci- 
mento desse tipo (Tabela 6). O mesmo ocorre para as médias do indicador do nível de vida, para as médias de pais que participam das reuniões na escola e para as médias de crianças que residem em lares uniparentais femininos.

\section{Resultados e discussões}

Os resultados das estimações para a probabilidade de o diretor da escola reportar ao menos uma agressão física cometida por um aluno estão representados na Tabela 7. A amostra é composta de 13.452 observações das escolas públicas, nos anos de 2007 e 2009, utilizando dados da Prova Brasil. Para considerar a natureza binária da variável dependente e a presença de efeitos não observados entre as escolas, estima-se um modelo logit de efeito fixo, através do estimador condicional de máxima verossimilhança que elimina $c_{i}$ da estimativa ao condicionar a distribuição de $y_{i}=\left(y_{i 1}, \ldots, y_{i T}\right)^{\prime}$ em $x_{i}, c_{i}$ e $\sum_{t=1}^{T_{i}^{i}} y_{i t}$.

Por esse método, não é possível avaliar diretamente os efeitos parciais das variáveis independentes sobre a probabilidade de resposta (Wooldridge, 2002). Por outro lado, é possível interpretar a magnitude dos coeficientes estimados por meio da oddsratio (DEE, 2005). Os resultados são similares aos resultados das estimativas de mínimos quadrados ordinários $(M Q O)$ baseadas em um modelo de probabilidade linear com efeito fixo, principalmente nas variáveis relacionadas ao ambiente escolar, que são significativas.

Por exemplo, no caso do modelo linear, o efeito estimado da variável agressão do professor sobre a variável dependente, agressão do aluno, é 0,27 pontos percentuais. Consideramos que a probabilidade de observar, na escola, pelo menos uma agressão cometida por aluno seja de 0,47 , que corresponde à proporção de escolas onde foram registradas tais agressões (Tabela 2). Dessa forma, a agressão física cometida por um professor altera a probabilidade de um aluno cometer uma ação violenta de 0,47 para 0,74 $(0,47+0,27=0,74)$. Os resultados das odds associadas a esses valores são:

$$
\frac{P_{i t}}{1-P_{i t}}=\frac{0,47}{1-0,47}=0,89
$$

e

$$
\frac{P_{i t}}{1-P_{i t}}=\frac{0,74}{1-0,74}=2,85
$$


Onde $P_{i t}$ é a probabilidade de a $i$-ésima escola registrar uma agressão cometida por um aluno, no período $t$. Dessa forma, a odds da escola que reportou pelo menos uma ação violenta do aluno, considerando que houve também agressão do professor é de 2,85 , e a odds considerando que não houve agressão do professor é de 0,89 .

A oddsratio é a razão entre as odds calculadas acima, ou seja, 3,2 (2,85 / 0,89 = 3,2), e corresponde ao crescimento na odds de ação violenta de um aluno, quando foi registrada uma agressão física cometida por um professor na escola (de 0,89 para 2,85). Esse resultado é similar a oddsratio de 3,54, estimada por meio do modelo logit de efeito fixo. Tal raciocínio pode ser feito para as demais variáveis analisadas e, assim, observar que os resultados das estimativas do modelo de probabilidade linear e do modelo logit são similares. A interpretação dos resultados será feita com base nas estimativas da oddsratio do modelo logit de efeito fixo, mais indicado por considerar a natureza binária da variável dependente.

A oddsratio associada à variável agressão do professor mostra que a possibilidade de o diretor da escola reportar pelo menos uma agressão física cometida por um aluno é 3,54 vezes maior em escolas onde foi registrada uma agressão física cometida por um professor. Esse resultado indica que a influência do professor na formação do aluno se dá também mediante o exemplo de comportamento. Isso pode ser uma evidência em favor da teoria da interação social, na qual os indivíduos baseiam suas decisões observando as ações de seus antecessores.

As variáveis que caracterizam o ambiente escolar com a presença da violência são: ocorrência de crimes contra o patrimônio, crimes contra a pessoa, tráfico de drogas e atuação de gangues. Crime contra o patrimônio não caracteriza uso da violência contra a pessoa; porém, a possibilidade de o diretor da escola reportar o comportamento violento de pelo menos um aluno onde foi reportado também esse tipo de crime é 1,46 vez maior. Isso pode estar evidenciando que, mesmo que a criança não presencie um ato de violência física, conviver em um ambiente com traços que caracterizam ações violentas pode levá-la a manifestar tal comportamento.

Valverde et al. (2005) argumenta que, quando atos desse tipo são repetitivos e ficam impunes, a ideia de cidadania e de confiança nas instituições é enfraquecida, quebrando as regras elementares de convivência. Esse argumento baseia-se em uma pesquisa sobre a violência escolar, enfocando prioritariamente as experiências e percepções de adolescentes e jovens em cinco 
capitais brasileiras em 2003. Os dados obtidos mostram a banalização de crimes contra o patrimônio no cotidiano das escolas, quando muitas vezes se identificam esses acontecimentos como brincadeira ou algo sem importância. No presente estudo, ao observarmos que crime contra o patrimônio pode levar a atos violentos contra pessoas, corroboramos o argumento de que tal comportamento não pode ser tratado como algo sem importância e devem ser tomadas providências quando esse tipo de ato é observado na escola.

Além disso, alguns estudos mostram que medidas de infraestrutura e o estado de conservação da escola estão associados a melhor desempenho escolar (Paes de Barros et al., 2001; Menezes-Filho, 2007). Os resultados deste artigo somam-se a esses estudos ao mostrar que preservar um bom ambiente escolar pode trazer ganhos de formação social do aluno.

A possibilidade de o diretor reportar o comportamento violento de pelo menos um aluno é 1,23 vez maior onde ocorreu um crime contra a pessoa dentro da escola e 1,52 vez maior onde houve tráfico de drogas nas dependências e no entorno da escola. $O$ tráfico de drogas pode interferir no comportamento do aluno no caso do consumo da droga, que altera sua conduta, propiciando o ato violento. Além disso, por ser uma atividade ilegal, o tráfico de drogas pode levar à perda da confiança nas instituições e propiciar outros tipos de violência, assim como ocorre nos casos de crime contra o patrimônio.

Já em escolas onde houve atuação de gangues nas dependências e no seu entorno, a possibilidade de o diretor reportar comportamento violento de pelo menos um aluno é 1,76 vez maior. Conforme Valverde et al. (2005), as gangues interferem no cotidiano das escolas em várias situações, como, por exemplo, quando se posicionam contra algum aluno, quando jovens entram na escola procurando algum "jurado de morte", ou quando brigam sobre a demarcação de territórios, gerando embates e rivalidades. É de se esperar que presenciar essas situações influencie o comportamento do aluno.

O segundo grupo de variáveis escolares analisadas está relacionado às medidas ou políticas de gestão escolar que podem contribuir para reduzir a manifestação do comportamento violento dos alunos. Observamos que a possibilidade de o diretor reportar pelo menos uma agressão física cometida por um aluno na escola é 0,86 vez menor em escolas que adotam alguma medida de segurança para proteger os alunos nas suas imediações. Esse é mais um resultado que pode ser uma evidência em favor da teoria da interação social, uma vez que, se o ambiente no entorno da escola for caracterizado com a presença da violência, entrar em contato com esse meio pode 
influenciar o jovem a reproduzir o mesmo comportamento dentro da escola. Nas escolas que promovem atividades artísticas e de esportes, a possibilidade de o diretor reportar o comportamento violento de pelo menos um aluno é 0,96 vez menor, o que é uma evidência de que tais atividades podem ser usadas com forma de socialização dos alunos, reduzindo a violência.

A possibilidade de o diretor reportar pelo menos uma agressão física cometida por um aluno em escolas que formam as turmas por nota é 0,90 vez menor. Logo, observar essa questão para formar as turmas pode evitar conflitos entre os alunos em função das suas características distintas de aprendizado. Já o coeficiente da variável turmas formadas por idade não foi significativo.

Observamos relação negativa entre a proporção de crianças que frequentaram a creche e o registro de comportamento agressivo de um aluno na escola. Se tal proporção aumentar um ponto percentual, a possibilidade de se observar a ação violenta de pelo menos um aluno na escola é 0,53 vez menor. Essa evidência está de acordo com a literatura que defende que intervenções educacionais precoces contribuem para reduzir a violência, uma vez que podem facilitar o processo de socialização da criança, torná-la mais paciente e desenvolver noções de moralidade e civilidade que aumentam a probabilidade de o indivíduo obedecer às leis (Becker, 1968; Becker; Mulligan, 1997; Heckman, 2000; Lochner, 2004).

No caso das variáveis relacionadas às características das famílias, o coeficiente da variável nível de vida apresentou sinal negativo, o que indica que, se a média desse índice nas escolas aumentar de uma unidade, a possibilidade de pelo menos um aluno na escola cometer uma agressão física será 0,98 vez menor.

Com relação à participação dos pais nas atividades escolares, observamos que, nas escolas onde a proporção de pais de alunos que participam das reuniões na escola é maior em um ponto percentual, a possibilidade de pelo menos um aluno manifestar o comportamento violento é 0,92 vez menor. Esse resultado está de acordo com o estudo de Donohue e Siegelman (1994), que observa que a maior participação dos pais nas atividades escolares dos filhos pode prevenir a criminalidade.

Observamos relação positiva entre a proporção de crianças que moram apenas com a mãe ou mulher responsável e o registro de comportamento agressivo de um aluno na escola. Se a proporção de alunos que residem em lares uniparentais femininos aumentar um ponto percentual, a possibilida- 
Tabela 7 Resultados das estimações para a probabilidade de o diretor reportar pelo menos uma agressão física cometida por pelo menos um aluno na escola, Brasil 2007 e 2009

\begin{tabular}{|c|c|c|c|}
\hline Variáveis & $\begin{array}{r}\text { Modelo logit } \\
\text { Parâmetro } \\
\end{array}$ & $\begin{array}{r}\text { Modelo logit } \\
\text { Oddsratio } \\
\end{array}$ & $\begin{array}{r}\text { Modelo linear } \\
\text { (Parâmetro) }\end{array}$ \\
\hline \multirow{2}{*}{ Agressão do professor } & $1,264^{* * *}$ & 3,54 & $0,270 * * *$ \\
\hline & $(0,025)$ & & $(0,041)$ \\
\hline \multirow{2}{*}{ Crime contra o patrimônio } & $0,375^{* * *}$ & 1,46 & $0,071^{* * *}$ \\
\hline & $(0,007)$ & & $(0,013)$ \\
\hline \multirow{2}{*}{ Crime contra a pessoa } & $0,208^{* * *}$ & 1,23 & $0,046^{* *}$ \\
\hline & $(0,010)$ & & $(0,018)$ \\
\hline \multirow{2}{*}{ Tráfico de drogas } & $0,418^{* * *}$ & 1,52 & $0,085^{* * *}$ \\
\hline & $(0,008)$ & & $(0,014)$ \\
\hline \multirow{2}{*}{ Atuação de gangues } & $0,564^{* * *}$ & 1,76 & $0,118^{* * *}$ \\
\hline & $(0,008)$ & & $(0,016)$ \\
\hline \multirow{2}{*}{ Medidas de segurança } & $-0,150^{* * *}$ & 0,86 & $-0,030^{* * *}$ \\
\hline & $(0,006)$ & & $(0,012)$ \\
\hline \multirow{2}{*}{ Atividade extracurricular } & $-0,043^{* * *}$ & 0,96 & $-0,008$ \\
\hline & $(0,010)$ & & $(0,019)$ \\
\hline \multirow{2}{*}{ Turmas por idade } & $-0,010$ & 0,99 & $-0,001$ \\
\hline & $(0,007)$ & & $(0,013)$ \\
\hline \multirow{2}{*}{ Turmas por nota } & $-0,108^{* * *}$ & 0,90 & $-0,018$ \\
\hline & $(0,013)$ & & $(0,026)$ \\
\hline \multirow{2}{*}{ Creche } & $-0,627^{* * *}$ & 0,53 & $-0,113$ \\
\hline & $(0,045)$ & & $(0,083)$ \\
\hline \multirow{2}{*}{ Nível de vida } & $-0,025^{* * *}$ & 0,98 & $-0,005^{* * *}$ \\
\hline & $(0,001)$ & & $(0,002)$ \\
\hline \multirow{2}{*}{ Reunião } & $-0,078 * *$ & 0,92 & $-0,020$ \\
\hline & $(0,040)$ & & $(0,073)$ \\
\hline \multirow{2}{*}{ Lar uniparental feminino } & $0,099 * *$ & 1,10 & 0,021 \\
\hline & $(0,044)$ & & $(0,086)$ \\
\hline \multirow{2}{*}{ Ano } & $0,054^{* * *}$ & 1,06 & 0,006 \\
\hline & $(0,004)$ & & $(0,008)$ \\
\hline Teste F & - & & 18,04 \\
\hline$x^{2}$ & $23.651,86$ & & - \\
\hline $\mathbf{N}^{\circ}$ de observações & 5.152 & & 13.452 \\
\hline
\end{tabular}

Fonte: Elaboração do autor com base nos microdados da Prova Brasil de 2007 e 2009.

Nota: ${ }^{* * *},{ }^{* *},{ }^{*}$ denotam significância ao nível de 1\%,5\% e 10\%, respectivamente. Valores entre parênteses representam o erro padrão. As estimativas foram ponderadas pelo número de alunos nas escolas. 
de de o diretor reportar a ação violenta de pelo menos um aluno na escola é 1,10 vez maior. Esses resultados estão de acordo com os estudos de Case e Katz (1991) e Levitt e Lochner (2000), que também observaram relação entre as variáveis de estrutura familiar e o comportamento dos jovens.

O resultado da variável binária de ano indica que a possibilidade de o diretor da escola registrar pelo menos uma agressão física é 1,06 vez maior no ano de 2009 em relação a 2007. Tal resultado aponta para o crescimento no número de escolas onde o diretor reportou pelo menos um caso de comportamento violento em que o agressor foi um aluno; porém, é importante lembrar que isso não implica um aumento no total de alunos que cometeram agressão física, uma vez que as informações do questionário da Prova Brasil não permitem diferenciar as escolas onde ocorreu apenas uma ação violenta daquelas em que ocorreram várias dessas ações.

\section{Conclusão}

Este estudo teve como objetivo analisar a influência de alguns elementos do ambiente escolar sobre a agressividade dos alunos. Os resultados indicaram que a possibilidade de o diretor da escola reportar pelo menos uma agressão física cometida por um aluno é 3,54 vezes maior em escolas onde foi registrada uma agressão física cometida por um professor. Isso pode ser uma evidência em favor da teoria da interação social, na qual o jovem observa a conduta dos professores e a considera como exemplo no processo de tomada de decisão. Por isso, destaca-se a importância de garantir assistência e boas condições de trabalho aos professores, para que esses possam lecionar com a segurança e a estabilidade emocional que requer a profissão de professor.

Outras variáveis que caracterizam a violência no ambiente escolar também apresentaram impacto significativo sobre a agressividade dos alunos. Entrar em contato com um meio onde prevalecem ações violentas tem influência direta sobre o comportamento do aluno dentro da escola. Sendo assim, as políticas públicas para reduzir o crime na vizinhança da escola podem contribuir significativamente para reduzir a agressividade dos alunos. Algumas medidas de gestão escolar também podem contribuir para facilitar a socialização dos alunos, como, por exemplo, distribuir as turmas por equivalência de nota ou promover atividades extracurriculares. 
Uma forma de avançar neste estudo seria encontrar bons instrumentos para as variáveis de violência na escola, uma vez que essas variáveis podem apresentar causalidade reversa se considerarmos que muitos alunos estudam em escolas próximas ao local de residência e, ao interagirem no ambiente ao redor da escola, podem influenciar o comportamento dos agentes externos.

\section{Referências}

ABRAMOVAY, M.; RUA, M. G. Violência nas escolas. Brasília: UNESCO, 2002. 80 p.

BANERJEE, A. V. A simple model of herd behavior. The Quarterly Journal of Economics, Oxford, v. 107, p. 797-817, 1992.

BANERJEE, A. V.; FUDENBERG, D. Word of mouth learning. Games and economic behavior. Amsterdã: Elsevier Science, p. 1-22, 2004.

BECKER, G. S. Crime and punishment: An economic approach. The Journal of Political Economy, Chicago, v. 76, n. 2, p. 169-217, 1968.

BECKER, G. S.; MULLIGAN, C. B. The endogenous determination of time preference. Quarterly Journal of Economics, Oxford, v. 112, n. 3, p. 729-758, Aug. 1997.

CASE, A.; KATZ, L. The company you keep: The effects of family and neighborhood on disadvantaged youths. NBER Working Paper, 3705. Cambridge: NBER, 1991. p. 1-41.

DEE, S. T. A teacher like me: Does race, ethnicity, or gender matter? The American Economic Review, Pittsburgh, v. 95, n. 2, p. 158-165, 2005.

DONOHUE, J.; SIEGELMAN, P. Is the United States at the optimal rate of crime? Mimeo, American Bar Foundation, 1994.

FARRINGTON, D. P. Childhood aggression and adult violence: Early precursors end later-life outcomes. In: PEPPLER, J; RUBIN K. (Ed.). The development and treatment of childhood aggression. Toronto: Psychology Press, 1990. p. 5-25.

FARRINGTON, D. P.; LOEBER, R. Epidemiology of juvenile violence. Child and Adolescent Psychiatric Clinics of North America, Cambridge, v. 9, n. 4, p. 733-748, 2000.

FREEMAN, R. B. The economics of crime. Handbook of Labor Economics. Amsterdã: Elsevier Science, 1999. p. 3530-3563.

GLAESER, E.; SACERDOTE, B.; SHEINKMNA, J. Crime and social interactions. Quarterly Journal of Economics, Oxford, v. 111, n. 445, p. 507-548, 1996.

GROGGER, J. Local violence and educational attainment. Journal of Human Resources, Madison, v. 32, n. 4, p. 659-682, 1997.

HEAVNER, D. L.; LOCHNER, L. Social networks and the aggregation of individual decisions. NBER Working Paper, W8979. Cambridge: National Bureau of Economic Research, 2002. 23 p.

HECKMAN, J. Policies to foster human capital, Research in Economics, Venezia, v. 54, n. 1, p. 3-56, 2000.

JACOB, B. A. LEFGREN, L. Are idle hands the devil's workshop? Incapacitation, Concentra- 
tion, and Juvenile Crime. American Economic Review, Pittsburgh, v. 93, n. 5, p. 1560-1577, Dec. 2003.

LEVITT, S. D.; LOCHNER L. The Determinants of Juvenile Crime. Mimeo, American Bar Foundation, 2000. p. 1156-1185.

LOCHNER, L. Education, work, and crime: A human capital approach. NBER Working Paper Series, 10478. Cambridge: National Bureau of Economic Research, 2004. 43 p. ().

MENEZES-FILHO, N. A. Os determinantes do desempenho escolar no Brasil. São Paulo: Instituto Futuro Brasil, IBMEC; Faculdade de Economia e Administração da Universidade de São Paulo. Sumário Executivo. 2007. 38 p.

MOCAN, H. N. REES, D. I. Economic conditions, deterrence and juvenile crime: Evidence from micro data. American Law and Economics Review, v. 7, n. 2, 2005.

PAES DE BARROS, R.; MENDONCA, R.; SANTOS, D. D.; QUINTAIS, G. Determinantes do desempenho educacional no Brasil. Texto para Discussão, 834. Brasília: Instituto de Pesquisa Econômica Aplicada, out. 2001. 38 p. Disponível em: <http://www.ipea.org.br>. Acesso em: 15 ago. 2001.

PAMPEL, F. C. Logistic regression: A primer. Sage University papers series on Quantitative Applications in the Social Sciences. Thousand Oaks, CA: Sage, 2000.p.7-132.

SAMPSON, R.; LAUB, J. Crime in the making: Pathways and turning points through life. Cambridge, MA: Harvard University Press, 1993. 31 p.

SEVERNINI, E.; FIRPO, S. The relationship between school violence and student proficiency. Texto para Discussão, 236. Escola de Economia de São Paulo da Fundação Getulio Vargas, 2009. Disponível em: <http://www.eesp.fgv.br/>Acesso em: 10 ago. 2010.

SPOSITO, M. P. Um breve balanço da pesquisa sobre violência na escola. Educação e Pesquisa, São Paulo, v. 27, n. 1, p. 87-103, jan./jun., 2001.

THOMPSON, P. Patent citations and the geography of knowledge spillovers: Evidence from inventor - and examiner-added citations. Review of Economics and Statistics, Cambridge, v. 88 , n. 2, p. 383-388, 2006.

VALVERDE, D. O.; BARBOSA D. T.; PEREIRA de PAULA F.; AVANCINI, M. M. P.; CASTRO, M. G. Cotidiano das escolas: Entre violências. Brasília: UNESCO; Observatório de Violência, Ministério da Educação, 2005. p. 249-294.

WOOLDRIDGE, J. M. Econometric analysis of cross section and panel data. Cambridge: MIT Press, 735 p., 2002.

\section{Sobre o autor}

KalincaLéiaBecker - kalincabecker@gmail.com

Universidade Federal de Santa Maria, Santa Maria, RS

Ana Lúcia Kassouf - anakassouf@usp.br

Universidade de São Paulo - ESALQ, São Paulo, SP

\section{Sobre 0 artigo}

Recebido em 26 de agosto de 2014. Aprovado em 22 de junho de 2015.

Este artigo recebeu financiamento do Programa Observatório da Educação CAPES/INEP. 


\section{Apêndice}

Tabela A1 Teste de Hausman comparando os modelos logit de efeito fixo e de efeito aleatório e os modelos logit de efeito fixo e logit convencional

\begin{tabular}{lrrrr}
\hline Variáveis & Efeito Fixo & Efeito aleatório & Logit convencional \\
\hline Agressão do professor & 1,2640 & 1,4412 & 1,2106 \\
\hline Crime contra o patrimônio & 0,3755 & 0,4726 & 0,4038 \\
\hline Crime contra a pessoa & 0,2082 & 0,3053 & 0,2628 \\
\hline Tráfico de drogas & 0,4179 & 0,6635 & 0,5739 \\
\hline Atuação de gangues & 0,5642 & 0,7752 & 0,6627 \\
\hline Medidas de segurança & $-0,1498$ & $-0,1144$ & $-0,0883$ \\
\hline Atividade extracurricular & $-0,0429$ & $-0,0526$ & $-0,0463$ \\
\hline Turmas por idade & $-0,0099$ & $-0,0425$ & $-0,0391$ \\
\hline Turmas por nota & $-0,1083$ & $-0,1959$ & $-0,1724$ \\
\hline Creche & $-0,6273$ & $-0,1656$ & $-0,1111$ \\
\hline Nível de vida & $-0,0246$ & $-0,0106$ & $-0,0079$ \\
\hline Reunião & $-0,0780$ & $-0,4043$ & $-0,3531$ \\
\hline Lar uniparental feminino & 0,0994 & $-0,3682$ & $-0,3582$ \\
\hline Ano & 0,0536 & 0,0125 & 0,0026 \\
\hline Teste de Hausman & & $8,861,96$ & $2.740,17$ \\
\hline$\rho$ & 0,00 & 0,00 & \\
\hline
\end{tabular}

Fonte: Elaboração do autor com base nos microdados da Prova Brasil. 